\title{
Minimally Invasive (Laparoscopic or Robotic) Reduced Port (Single Port) Distal Pancreatectomy
}

\author{
Chang Moo Kang, M.D., Ph.D. \\ Division of Hepatobiliary and Pancreatic Surgery, Department of Surgery, Yonsei University College of Medicine, Seoul, Korea
}

\begin{abstract}
In spite of lack of randomized control study, laparoscopic distal pancreatectomy (DP) is regarded as appropriate treatment in managing benign and low grade malignant tumor in distal part of the pancreas. With the advance of laparoscopic skills, innovative instruments, and perioperative management, clinical effort to reduce the access injury for laparoscopic DP has been attempted to enhance the cosmetic effect and the benefit of minimally invasive surgery. Due to inborn technical limitation of laparoscopic surgical system, it is not easy to perform laparoscopic reduced port-or single port-distal pancreatectomy (LRP/LSP-DP) in daily routine clinical practice, however, surgical technique for safe and effective LRP/LSP-DP has been developed. Till now, only a few experts reported the technical feasibility and safety of LRP/LSP-DP in selected patients. According to literature review, the number of the patients who underwent LRP/LSP-DP seems to gradually increase. In this moment, surgical experiences may be too limited to reach the conclusion, but, with the help of robotic surgical system, LRP/LSP-DP has potential room for further investigation. Therefore, minimally invasive surgeons need to pay attention to this innovative movement. In this review, currently available surgical techniques for LRP/LSP-DP has been summarized with some future perspectives on this technique.
\end{abstract}

Keywords: Laparoscopic, Robotic, Reduced-port, Single-port, Pancreatectomy

This is an Open Access article distributed under the terms of the Creative Commons Attribution Non-Commercial License (http:// creativecommons.org/licenses/by-nc/4.0/) which permits unrestricted non-commercial use, distribution, and reproduction in any medium, provided the original work is properly cited.
Received February 8, 2017

Revised March 6, 2017

Accepted March 6, 2017

Corresponding author

Chang Moo Kang

Division of Hepatobiliary and

Pancreatic Surgery, Department

of Surgery, Yonsei University

College of Medicine, 50 Yonsei-ro,

Seodaemun-gu, Seoul 03722, Korea

Tel: +82-2-2228-2135

Fax: +82-2-313-8289

E-mail: cmkang@yuhs.ac

\section{INTRODUCTION}

Minimally invasive elective surgery, both laparoscopic and robotic, has replaced most traditional surgical procedures; however, because the pancreas is located in the retroperitoneal space behind the stomach, it is difficult to access using a laparoscopic approach. In addition, there are several important blood vessels around the pancreas, including the splenic artery, common hepatic artery, superior mesenteric vein, splenic vein, and portal vein. Even small tributary vessels emerging from these major vessels supplying the pancreas can be critical sources of massive bleeding during a laparoscopic dissection, which then obscure the operative field. This can potentially increase intraoperative risk. These are reasons why laparoscopic pancreatic surgery started later and advanced slowly compared to other general surgical fields., ${ }^{1,2}$ However, with the advance of laparoscopic techniques and instruments, laparoscopic pancreatectomy has become increasingly common. More specifically, laparoscopic distal pancreatectomy (DP) is regarded as an appropriate surgical option to treat benign and low-grade malignant lesions presenting in the left side of the pancreas. Even though there are no randomized controlled studies comparing laparoscopic DP and open DP, an increasing number of case reports and literatures strongly suggest that the perioperative outcomes after laparoscopic DP are better than those after open DP in terms of hospital stay length and 
Table 1. Recently published meta-analysis comparing LDP with open DP

\begin{tabular}{|c|c|c|c|c|c|c|c|c|}
\hline Author, year & $\begin{array}{c}\mathrm{N} \\
\text { (study) }\end{array}$ & $\underset{\text { (patients) }}{\mathrm{N}}$ & $\begin{array}{l}\text { Op time, } \\
p \text { value }\end{array}$ & $\begin{array}{c}\text { EBL, } \\
p \text { value }\end{array}$ & $\begin{array}{c}\mathrm{LOH} \\
p \text { value }\end{array}$ & $\begin{array}{c}\text { Morbidity } \\
p \text { value }\end{array}$ & $\begin{array}{l}\text { POPF } \\
p \text { value }\end{array}$ & $\begin{array}{c}\text { Mortality } \\
p \text { value }\end{array}$ \\
\hline $\begin{array}{l}\text { Mehrabi, et al. } \\
2015^{4}\end{array}$ & 29 & 3,701 & $\begin{array}{c}\mathrm{LDP}=0 \mathrm{PD} \\
0.22\end{array}$ & $\begin{array}{c}\quad \mathrm{LDP}<0 \mathrm{DPP} \\
\quad<0.01\end{array}$ & $\begin{array}{c}\mathrm{LDP}<0 \mathrm{PPD} \\
<0.01\end{array}$ & $\begin{array}{c}\mathrm{LDP}=0 \mathrm{DPO} \\
0.50\end{array}$ & $\begin{array}{c}\mathrm{LDP}=0 \mathrm{DP} \\
0.46\end{array}$ & $\begin{array}{c}\mathrm{LDP}=0 \mathrm{DP} \\
0.33\end{array}$ \\
\hline $\begin{array}{l}\text { Nakamura, et al. } \\
2013^{21}\end{array}$ & $24+3$ & 2,904 & $\begin{array}{c}\mathrm{LDP}=0 \mathrm{PD} \\
0.11\end{array}$ & $\begin{array}{c}\mathrm{LDP}<0 \mathrm{DPP} \\
<0.0001\end{array}$ & $\begin{array}{c}\mathrm{LDP}<0 \mathrm{DP} \\
<0.0001\end{array}$ & $\begin{array}{c}\mathrm{LDP}<0 \mathrm{DP} \\
0.018\end{array}$ & $\begin{array}{c}\mathrm{LDP}=0 \mathrm{DPP} \\
0.87\end{array}$ & $\begin{array}{c}L D P=0 D F \\
0.16\end{array}$ \\
\hline $\begin{array}{l}\text { Jin, et al. } \\
2012^{22}\end{array}$ & 15 & 1,456 & $\begin{array}{c}\mathrm{LDP}=0 \mathrm{PD} \\
0.19\end{array}$ & $\begin{array}{l}\mathrm{LDP}<0 \mathrm{DP} \\
<0.00001\end{array}$ & $\begin{array}{l}\text { LDP }<0 D P \\
<0.00001\end{array}$ & NA & $\begin{array}{c}L D P=0 D P \\
0.11\end{array}$ & $\begin{array}{c}\mathrm{LDP}=0 \mathrm{DP} \\
0.46\end{array}$ \\
\hline $\begin{array}{l}\text { Sui, et al. } \\
2012^{23}\end{array}$ & 19 & 1,935 & $\begin{array}{c}\mathrm{LDP}>0 \mathrm{PD} \\
0.02\end{array}$ & $\begin{array}{c}\mathrm{LDP}<0 \mathrm{DP} \\
<0.001\end{array}$ & $\begin{array}{c}\mathrm{LDP}<0 \mathrm{DP} \\
<0.001\end{array}$ & $\begin{array}{c}\mathrm{LDP}<0 \mathrm{DP} \\
0.001\end{array}$ & $\begin{array}{c}\mathrm{LDP}=0 \mathrm{DP} \\
0.66\end{array}$ & $\begin{array}{c}\mathrm{LDP}=0 \mathrm{DP} \\
0.61\end{array}$ \\
\hline $\begin{array}{l}\text { Xie, et al. } \\
2012^{24}\end{array}$ & 9 & 1,341 & $\begin{array}{c}\mathrm{LDP}>0 \mathrm{PD} \\
0.005\end{array}$ & NA & $\begin{array}{c}\mathrm{LDP}<0 \mathrm{DP} \\
0.00\end{array}$ & $\begin{array}{c}\mathrm{LDP}=0 \mathrm{DPO} \\
0.178\end{array}$ & $\begin{array}{c}\mathrm{LDP}=0 \mathrm{DP} \\
0.983\end{array}$ & NA \\
\hline $\begin{array}{l}\text { Venkat, et al. } \\
2012^{25}\end{array}$ & 18 & 1,814 & $\begin{array}{c}\mathrm{LDP}=0 \mathrm{PD} \\
0.30\end{array}$ & $\begin{array}{c}\mathrm{LDP}<0 \mathrm{DP} \\
0.003\end{array}$ & $\begin{array}{c}\mathrm{LDP}<0 \mathrm{DPP} \\
<0.001\end{array}$ & $\begin{array}{c}\mathrm{LDP}<0 \mathrm{DPO} \\
0.01\end{array}$ & $\begin{array}{c}L D P=0 D P \\
0.50\end{array}$ & $\begin{array}{c}\mathrm{LDP}=0 \mathrm{DP} \\
0.43\end{array}$ \\
\hline $\begin{array}{c}\text { Jusoh, et al. } \\
2011^{26}\end{array}$ & 13 & 1,091 & $\begin{array}{c}\mathrm{LDP}=0 \mathrm{PD} \\
\mathrm{NS}\end{array}$ & $\begin{array}{c}\mathrm{LDP}<0 \mathrm{DP} \\
<0.001\end{array}$ & $\begin{array}{c}\mathrm{LDP}<0 \mathrm{DP} \\
<0.001\end{array}$ & $\begin{array}{c}\mathrm{LDP}<0 \mathrm{DPO} \\
0.007\end{array}$ & $\begin{array}{c}L D P=0 D P \\
0.154\end{array}$ & $\begin{array}{c}L D P=0 D F \\
1.000\end{array}$ \\
\hline $\begin{array}{l}\text { Nigri, et al. } \\
2011^{27}\end{array}$ & 10 & 729 & $\begin{array}{c}\mathrm{LDP}=0 \mathrm{PD} \\
0.17\end{array}$ & $\begin{array}{c}\mathrm{LDP}<0 \mathrm{DP} \\
\mathrm{NA}\end{array}$ & $\begin{array}{c}\mathrm{LDP}<0 \mathrm{DP} \\
\mathrm{NA}\end{array}$ & $\begin{array}{c}L D P<0 D P \\
N A\end{array}$ & $\begin{array}{c}L D P=0 D P \\
N A\end{array}$ & $\begin{array}{c}\mathrm{LDP}=0 \mathrm{DP} \\
\quad \mathrm{NA}\end{array}$ \\
\hline
\end{tabular}

$\mathrm{LDP}=$ laparoscopic distal pancreatectomy; ODP = open distal pancreatectomy; EBL = estimated blood loss; $\mathrm{LOH}=$ length of hospital stay; POPF = postoperative pancreatic fistula; NA = not available.

estimated intraoperative blood loss. Above all, cosmetic effects from laparoscopic port incisions have not been evaluated and need to be considered when interpreting meta-analysis data (Table 1). It is still being debated whether randomized controlled studies are needed to provide scientific evidence for which surgical approach is superior. ${ }^{3,4}$

Recently, some expert surgeons have tried to reduce the number of trocars in conventional laparoscopic surgery to enhance LDP cosmetic and minimally invasive effects. It seems that reduced-port or single-port laparoscopic surgery is frequently performed for standard laparoscopic procedures including appendectomies, cholecystectomies, and colectomies. ${ }^{5-7}$ Barbaros et al..$^{8}$ reported the first single-incision laparoscopic DP performed in a 59-year-old female to treat pancreatic metastasis from renal cell carcinoma. Since then, the number of cases treated with laparoscopic single port (LSP) or laparoscopic reduced port (LRP) DP procedures has increased (Fig. 1).

In this review, we summarize the currently available literatures reporting laparoscopic single-port or reduced-port distal pancreatectomy, including current technical advances and $\mathrm{fu}^{-}$ ture trajectories of these procedures.

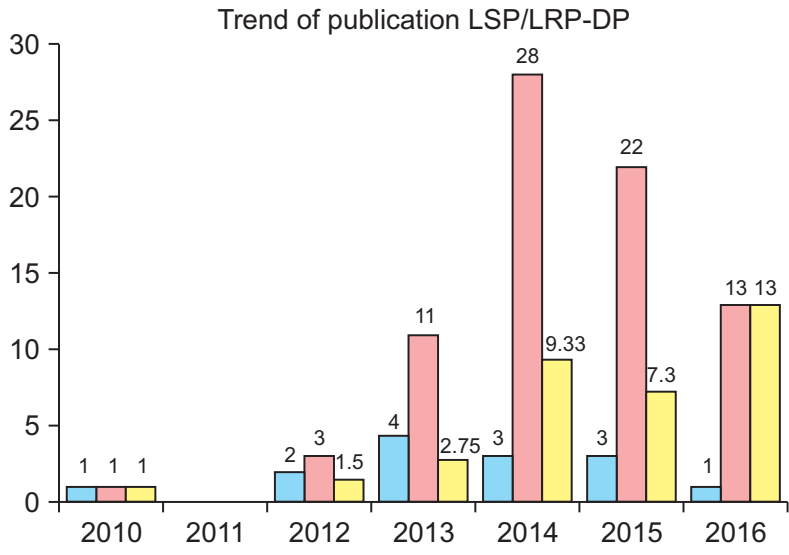

Fig. 1. Chronological trends for publications reporting LSP/LRP-DP on PubMed and KoreaMed. Scientific reports on laparoscopic DP are gradually increasing. Of note, the number of patients per published report during one year is also increasing (yellow). Four recent publications present a comparative analysis with conventional LDP. Blue column $=$ number of publications; Red column $=$ number of patients; Yellow column $=$ average patients per publication.

\section{CURRENTLY AVAILABLE SURGICAL PLATFORMS AND SHORT-TERM OUTCOMES}

When reviewing the publications reporting laparoscopic 


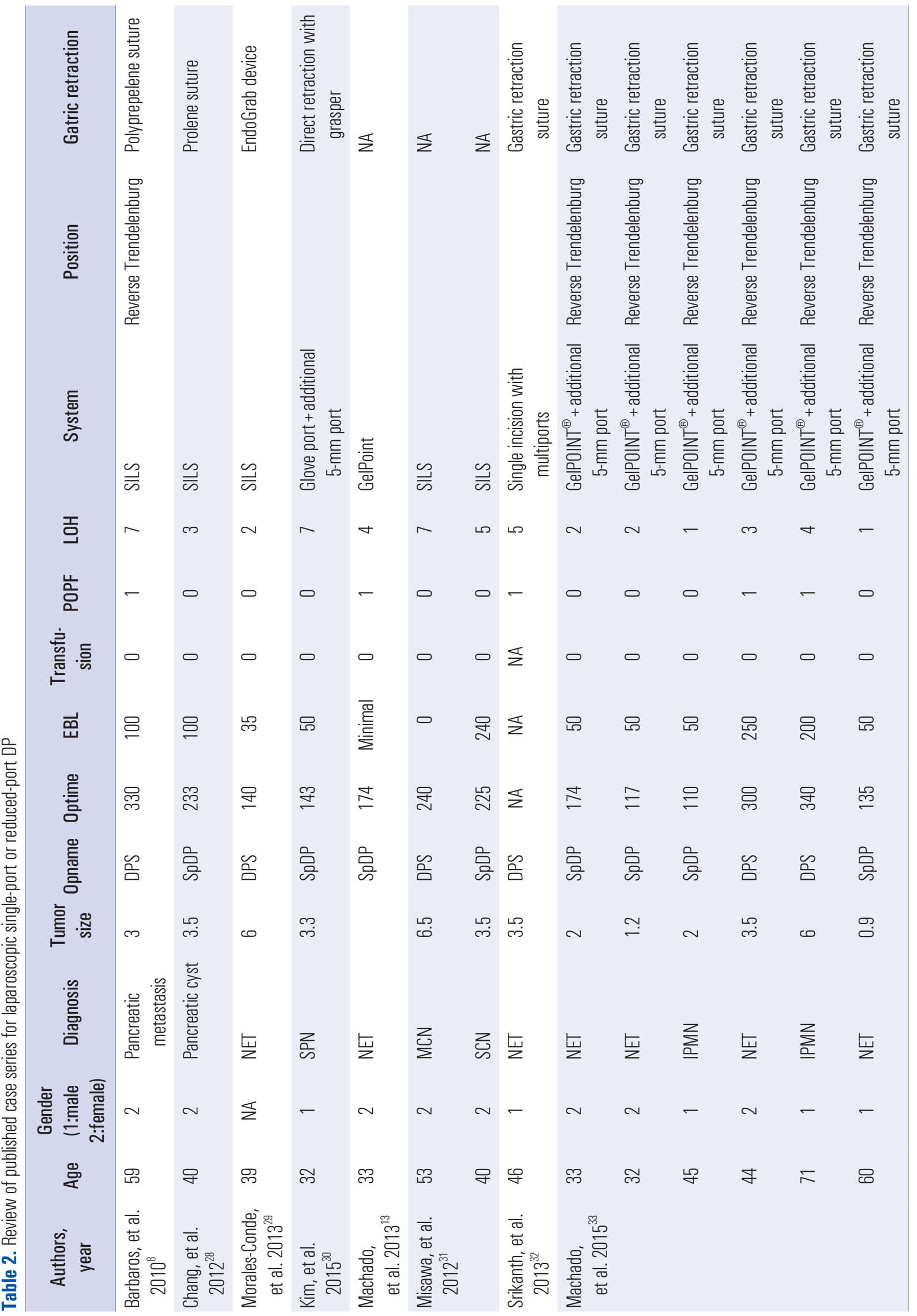




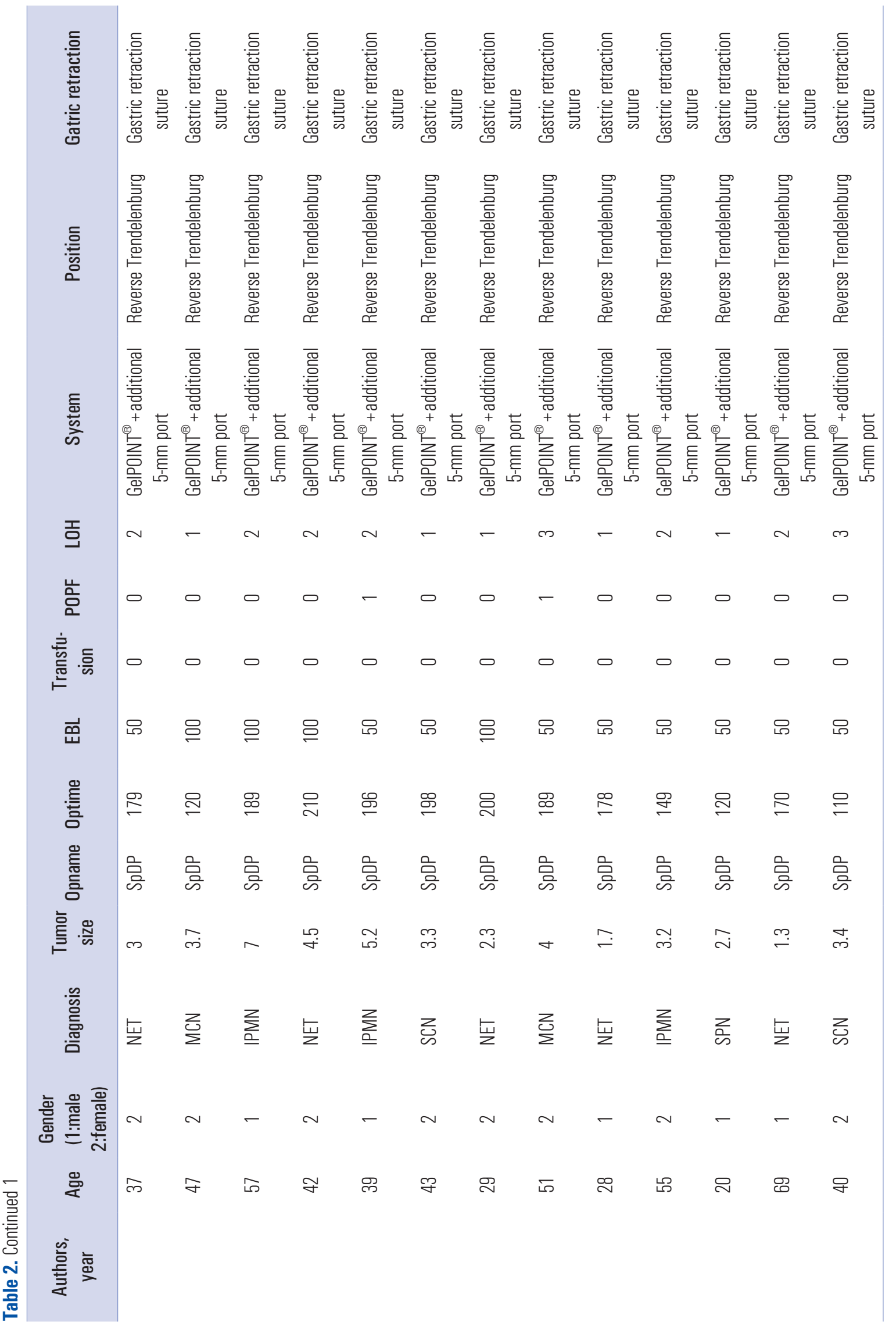




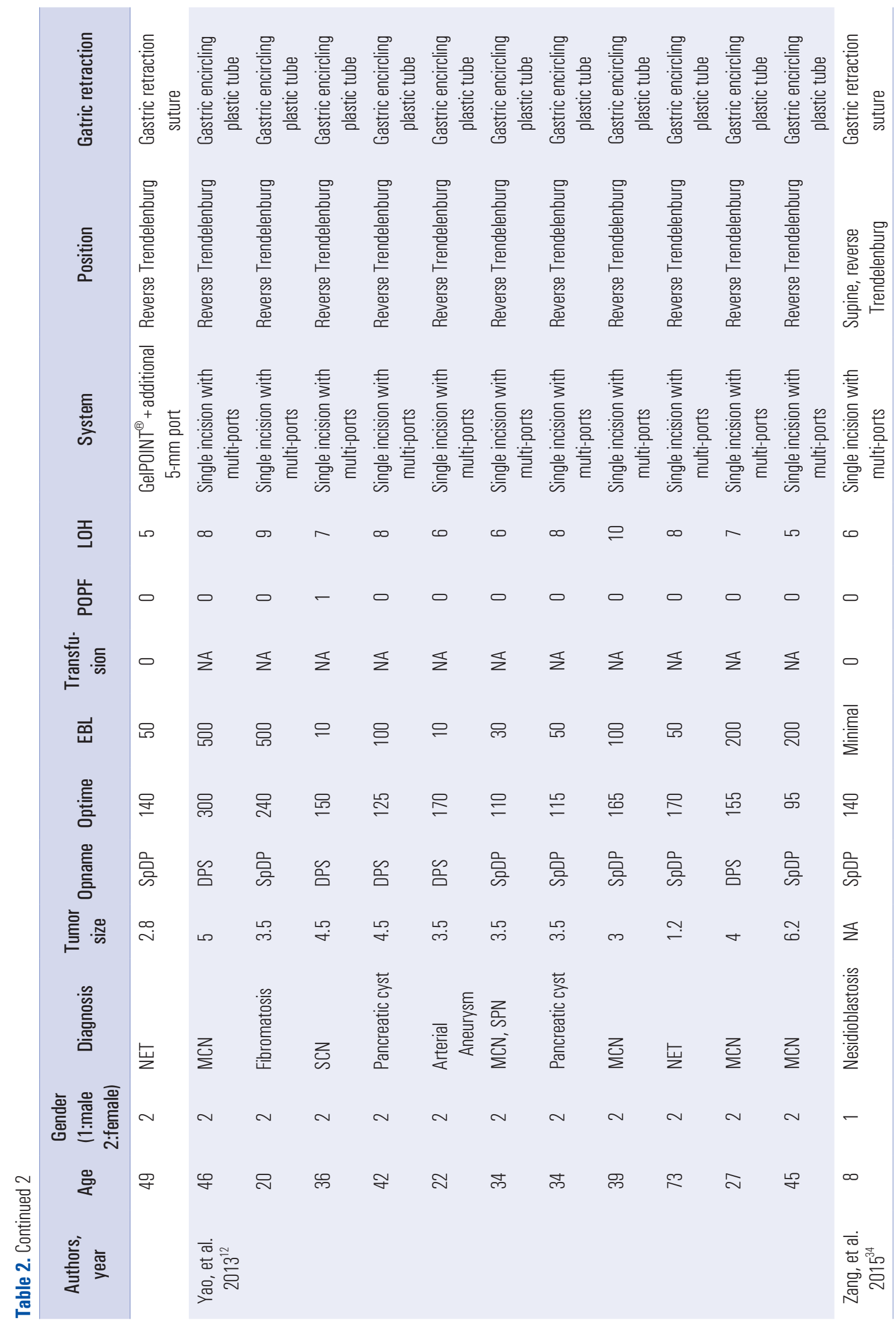



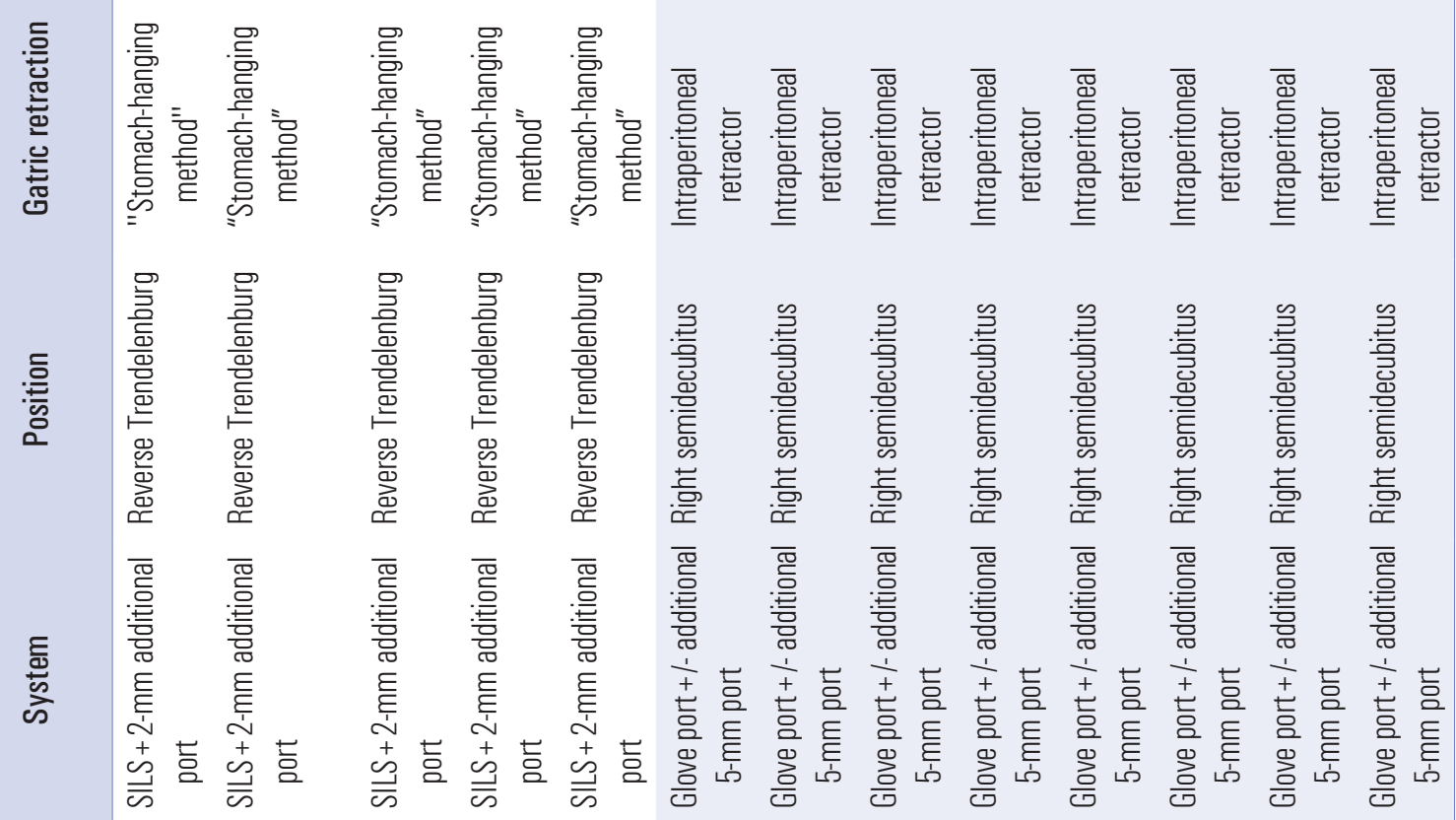

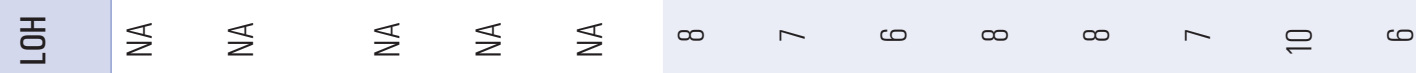

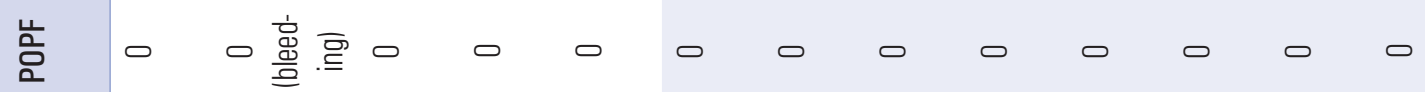

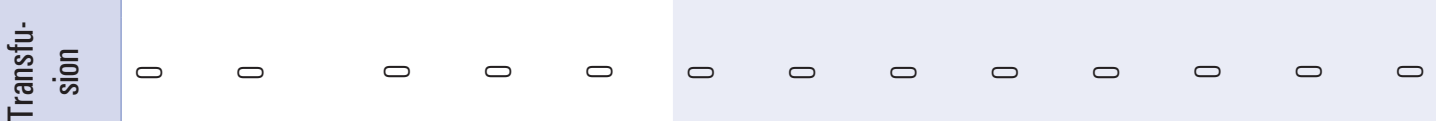

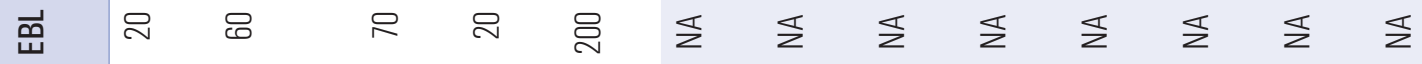

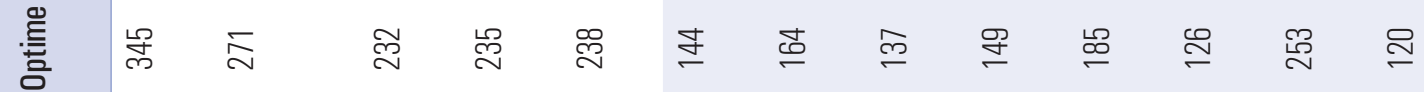

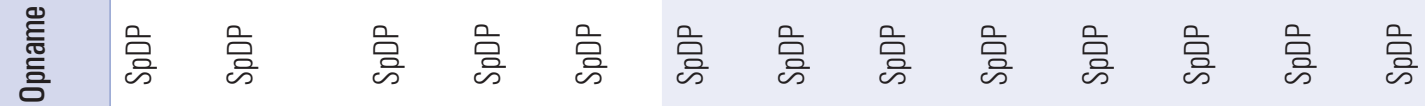

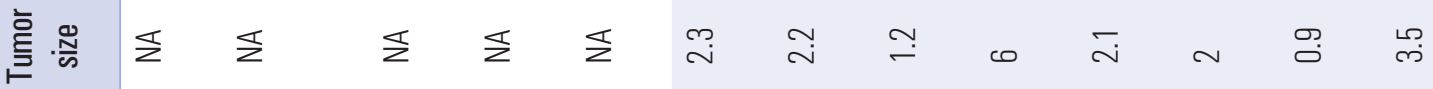

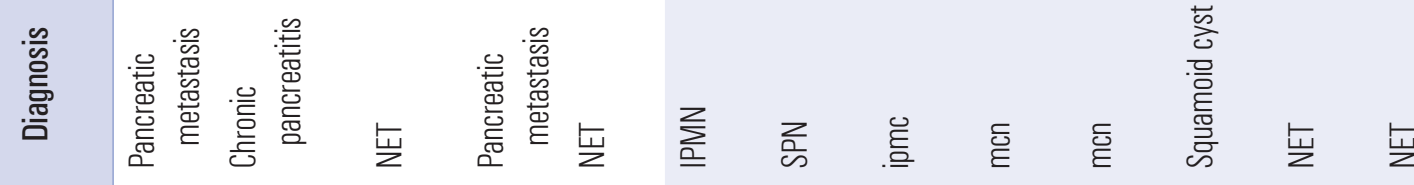

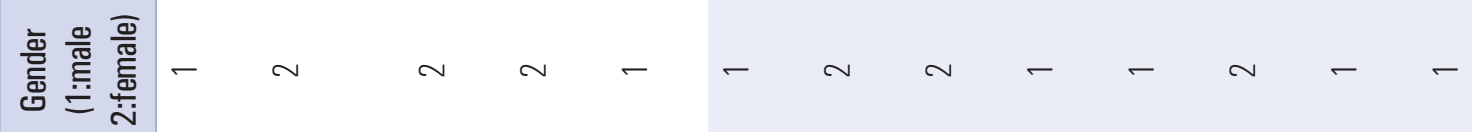

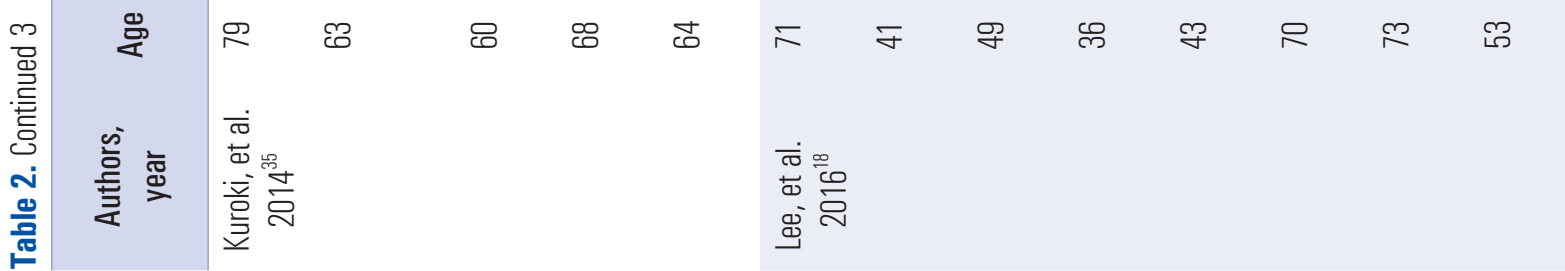




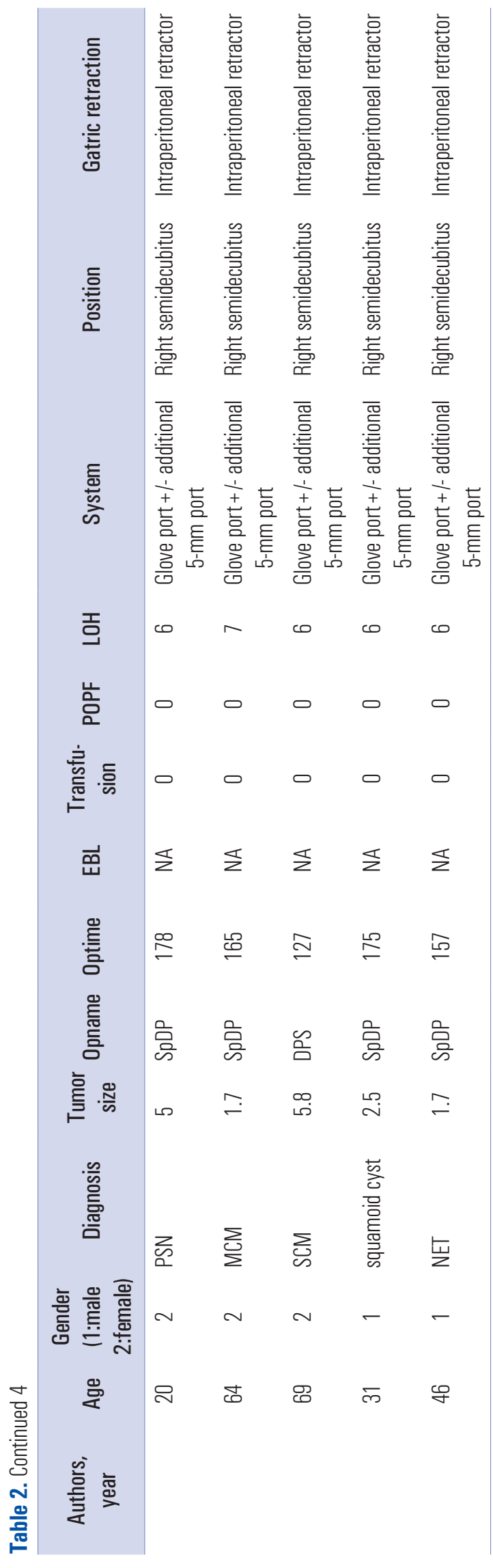

single port (LSP) or reduced port (LRP)-DP, a total of eight case reports and eight case series were identified in PubMed and KoreaMed. Among them, 12 publications described individual patient short-term perioperative outcomes, and a total of 58 patients were selected to evaluate perioperative outcomes after LSP/LRP-DP (Table 2). There were four retrospective $e^{9-12}$ comparative analyses between LSP/LRP-DP and conventional LDP. The most frequently used surgical system for LRP- DP was single-port with an additional 2-mm or 5-mm assist port. Pure LSP-DP was performed in only 14 patients (24.1\%). The success rate for LSP/LRP-DP was very high. Conversion to multiport conventional laparoscopic DP was reported in just two patients $(3.4 \%)$. Several methods for facilitating pancreas exposure were described. These included using sutures for gastric retraction, a plastic tube for gastric circling, and the use of an intraperitoneal retractor, or direct retraction with a laparoscopic grasper. Spleen-preserving DP is known to be a time and labor consuming procedure, and thus, an advanced laparoscopic technique is required for preserving the spleen during LDP. However, it is interesting to note that a spleenpreserving procedure was performed even in 46 patients (78\%).

A summary of perioperative outcomes showed that $20 \mathrm{pa}^{-}$ tients were male, and 37 were female with a mean age of 45.9 \pm 16.0 years (gender information was missing in one report ${ }^{13}$ ). Most pathologic diagnoses were benign or borderline malignant tumors of the pancreas with a mean tumor diameter of $3.4 \pm 1.6 \mathrm{~cm}$. Only four patients $(6.9 \%)$ were found to have malignant tumors (intraductal papillary mucinous neoplasm with cancerous transformation $(\mathrm{n}=1)$ and pancreatic metastasis $(n=3))$. The mean operation time was $181.5 \pm 60.8 \mathrm{~min}$, and

Table 3. Comparative analysis of laparoscopic single-port and reducedport DP

\begin{tabular}{lccr}
\hline & $\begin{array}{c}\text { LSP.DP } \\
\text { (N=28) }\end{array}$ & $\begin{array}{c}\text { LRP-DP } \\
\text { (N=30) }\end{array}$ & $p$ value \\
\hline Age & $43.3 \pm 15.9$ & $48.2 \pm 16.0$ & 0.250 \\
\hline Gender (Male:Female) & $8 / 19^{*}$ & $12 / 18$ & 0.413 \\
\hline Tumor size & $3.3 \pm 1.5$ & $3.4 \pm 1.7$ & 0.855 \\
\hline $\begin{array}{l}\text { Spleen preservation } \\
\text { (Yes/No) }\end{array}$ & $19 / 9$ & $27 / 3$ & 0.038 \\
\hline Operation Time (min) & $175.5 \pm 58.4$ & $186.9 \pm 63.3$ & 0.484 \\
\hline EBL (ml) & $139.1 \pm 158.2$ & $75.8 \pm 56.6$ & 0.141 \\
\hline LOH (days) & $6.6 \pm 1.9$ & $3.0 \pm 2.2$ & $<0.001$ \\
\hline POPF (Yes/No) & $4 / 24$ & $26 / 4$ & 1.000 \\
\hline $\begin{array}{c}\text { Conversion to } \\
\text { Conventional DP }\end{array}$ & 2 & 0 & 0.229 \\
\hline
\end{tabular}

${ }^{*}$ Missing gender data in one report. 
the mean estimated intraoperative blood loss was $99.9 \pm 109.9$ $\mathrm{ml}$. No patients required intraoperative transfusion. The mean hospital stay was $4.9 \pm 2.7$ days. There was no surgery-related mortality. Comparative analysis between LSP-DP and LRPDP showed that the spleen preserving rate was much higher $(p=0.038)$ and that the hospital stay was reduced $(6.6 \pm 1.9$ days, vs. 3.0 \pm 2.2 days, $p<0.001$ ) in LRP-DP (Table 3). This suggests that LRP-DP may be more reliable in selected DP cases requiring advanced surgical techniques. There were no significant differences between the two groups in terms of age, gender, tumor size, and postoperative pancreatic fistula formation. In LSP-DP, only two patients (7.1\%) were found to convert to conventional laparoscopic DP, and four cases (14.3\%) required an additional port (conversion to LRP-DP) for safe completion of the operation.

After taking potential publication bias into account, current published data on LSP/LRP-DP carefully suggest that (1) both LSP-DP and LRP-DP are feasible and safe in select patients and that (2) LRP-DP seems to be more effective in spleenpreserving procedures and enhances postoperative recovery.

\section{COMPARATIVE ANALYSIS BETWEEN LSP/ RP-DP AND CONVENTIONAL LDP}

There are only four studies which compared the perioperative outcomes between LSP/LRP-DP and conventional DP, including the most recent report by Lee. ${ }^{11}$ Among them, two ${ }^{10,11}$ were reported by members of Korean Society of Endoscopic and Laparoscopic Surgery (KSELS). ${ }^{14}$ The perioperative outcomes investigated in each study are summarized in Table 4. Even though the conclusions derived from these studies were based on a limited number of the cases and retrospective study designs associated with unintended selection bias, all studies indicated that LSP/LRP-DP was comparable to conventional DP in patients who required DP for benign and borderline (low grade) malignant tumors in distal pancreas.

The technical difficulty of the procedure and the resulting stress for the surgeon were not evaluated in these studies, which will continue to be the main obstacles to make LRP/ LSP-DP routine in clinical practice. Technical advances and more surgical experiences are needed to define the potential role of LSP/LRP-DP in minimally invasive pancreatic surgery.

Table 4. Review of comparative analyses between LSP-DP/ LRP-DP and conventional LDP (C-LDP)

\begin{tabular}{|c|c|c|c|c|c|c|c|c|c|}
\hline & \multicolumn{2}{|c|}{$\begin{array}{l}\text { Haugvik, et al. } \\
2013^{9}\end{array}$} & \multicolumn{2}{|c|}{$\begin{array}{l}\text { Yao, et al. } \\
2014^{12}\end{array}$} & \multicolumn{2}{|c|}{$\begin{array}{c}\text { Han, et al. }{ }^{*} \\
2014^{10}\end{array}$} & \multicolumn{3}{|c|}{$\begin{array}{l}\text { Lee, et al. }{ }^{*} \\
2016^{11}\end{array}$} \\
\hline & $\begin{array}{c}\text { LSP.DP } \\
(\mathrm{n}=8)\end{array}$ & $\begin{array}{l}\text { C-LDP } \\
(\mathrm{n}=16)\end{array}$ & $\begin{array}{l}\text { LSP-DP } \\
(\mathrm{n}=14)\end{array}$ & $\begin{array}{l}\text { C-LDP } \\
(\mathrm{n}=76)\end{array}$ & $\begin{array}{l}\text { LSP-DP } \\
(\mathrm{n}=12)\end{array}$ & $\begin{array}{l}\text { C-LDP } \\
(\mathrm{n}=28)\end{array}$ & $\begin{array}{c}\text { LSP-DP } \\
(\mathrm{n}=8)\end{array}$ & $\begin{array}{l}\text { LRP.DP } \\
(n=5)\end{array}$ & $\begin{array}{l}\text { C-LDP } \\
(n=27)\end{array}$ \\
\hline Surgical System & \multicolumn{2}{|c|}{ Multi-instrument access port } & \multicolumn{2}{|c|}{$\begin{array}{l}\text { Single incision with } \\
\text { multiport technique }\end{array}$} & \multicolumn{2}{|c|}{ Glove port } & \multicolumn{3}{|c|}{ Custom-made glove port } \\
\hline Age & $\begin{array}{c}65 \\
(35 \sim 74)\end{array}$ & $\begin{array}{c}61 \\
(44 \sim 81)\end{array}$ & $\begin{array}{c}40.2 \\
(20 \sim 73)\end{array}$ & $\begin{array}{c}50.4 \\
(35 \sim 65)\end{array}$ & $61.3 \pm 17.2$ & $49.1 \pm 15.8^{\dagger}$ & $50.8 \pm 14.4$ & $52.0 \pm 22.8$ & $55.0 \pm 14.9$ \\
\hline $\mathrm{BMI}$ & $\begin{array}{c}25.1 \\
(20.2 \sim 32.2)\end{array}$ & $\begin{array}{c}25.0 \\
(18.5 \sim 30.1)\end{array}$ & $\begin{array}{c}22.6 \\
(18.4 \sim 27)\end{array}$ & $\begin{array}{c}23.3 \\
(21.3 \sim 25.2)\end{array}$ & $23.5 \pm 4.6$ & $23.6 \pm 4.0$ & $23.1 \pm 1.8$ & $23.4 \pm 5.1$ & $23.3 \pm 3.0$ \\
\hline Tumor size (cm) & $\begin{array}{c}2.1 \\
(1.0 \sim 4.5)\end{array}$ & $\begin{array}{c}3.1 \\
(1.0 \sim 6.5)\end{array}$ & $\begin{array}{c}4.3 \\
(1.2 \sim 11)\end{array}$ & $\begin{array}{c}3.7 \\
(0.7 \sim 6)\end{array}$ & $3.8 \pm 1.8$ & $3.4 \pm 2.5$ & $1.9 \pm 0.9$ & $4.2 \pm 2.0$ & $3.2 \pm 2.1$ \\
\hline Operation time (min) & $\begin{array}{c}145 \\
(98 \sim 223)\end{array}$ & $\begin{array}{c}137 \\
(73 \sim 196)\end{array}$ & $166.4 \pm 57.4$ & $202.1 \pm 122.5$ & $279.8 \pm 52.0$ & $186.9 \pm 86.6$ & $142 \pm 35$ & $152 \pm 20$ & $180 \pm 48$ \\
\hline EBL (ml) & $\begin{array}{c}225 \\
(30 \sim 400)\end{array}$ & $\begin{array}{c}200 \\
(50 \sim 500)\end{array}$ & $157.1 \pm 162.4$ & $168.6 \pm 157.4$ & $185 \pm 125$ & $334 \pm 468$ & $100 \pm 41^{5}$ & $152 \pm 20$ & $180 \pm 48$ \\
\hline Conversion & \multicolumn{2}{|c|}{ None } & \multicolumn{2}{|c|}{1 (to C-DPS) } & \multicolumn{2}{|c|}{2 (to C-LDP) } & \multicolumn{3}{|c|}{$\begin{array}{c}4 \text { (to LDR-DP), \& } \\
1 \text { (to C-LDP) }\end{array}$} \\
\hline Complication & 4 & 5 & 1 & 0 & 5 & 7 & 1 & 3 & 5 \\
\hline POPF & 2 & 2 & NA & NA & 2 & 2 & 0 & 0 & 0 \\
\hline LOH (days) & $6(3 \sim 5)$ & $6(2 \sim 16)$ & $7.6 \pm 1.4$ & $9.0 \pm 3.0$ & $12.2 \pm 5.4$ & $8.3 \pm 4.7^{\ddagger}$ & $6.9 \pm 0.9$ & $7.0 \pm 1.0$ & $6.5 \pm 1.5$ \\
\hline
\end{tabular}

${ }^{*}$ Data from the members of KSELS. ${ }^{\dagger} p=0.035,{ }^{\ddagger} p=0.028,{ }^{\S} p=0.035$. 


\section{POTENTIAL TECHNIOUE: ROBOTIC SINGLE SITE PLUS ONE PORT DISTAL PANCREATECTOMY}

Despite the increasing number of laparoscopic DPs being performed and the advance of laparoscopic instruments, the fatigue and stress resulting from limited motion for instrument manipulation in the narrow surgical space (in current single port system) needs to be considered when performing LSP/ LRP-DP. Therefore, in order to improve intraoperative surgical quality, technical innovation is essential. In theory, robotic surgical systems can overcome the limitations of laparoscopic surgery. ${ }^{15,16}$ This technology may work even with LSP/RP-DP.

A robotic single-site surgical system has been introduced to facilitate laparoscopic single-port surgery. ${ }^{17-19}$ Additionally the stable, 3-D operation field can enhance a surgeon's ergonomic environment. This enables surgeons to avoid the situation of right and left disorientation for triangular configuration during laparoscopic single-port surgery. It is thought that most intraoperative stress and fatigue results from the mechanics of the laparoscopic single-port surgical system. However, the robotic surgical system automatically calculates the movement of the surgeon's console with the help of specially designed curved trocars and semi-flexible instruments, making it possible for the surgeon's right and left hand to control the rightand left-sided screen instruments even if the instrument is attached to the left and right robotic arm, respectively. ${ }^{18,20}$ If an additional robotic arm is added through another trocar in the abdomen, a wrist-like motion of instrument can be produced in the robotic single-site surgical system allowing for a more
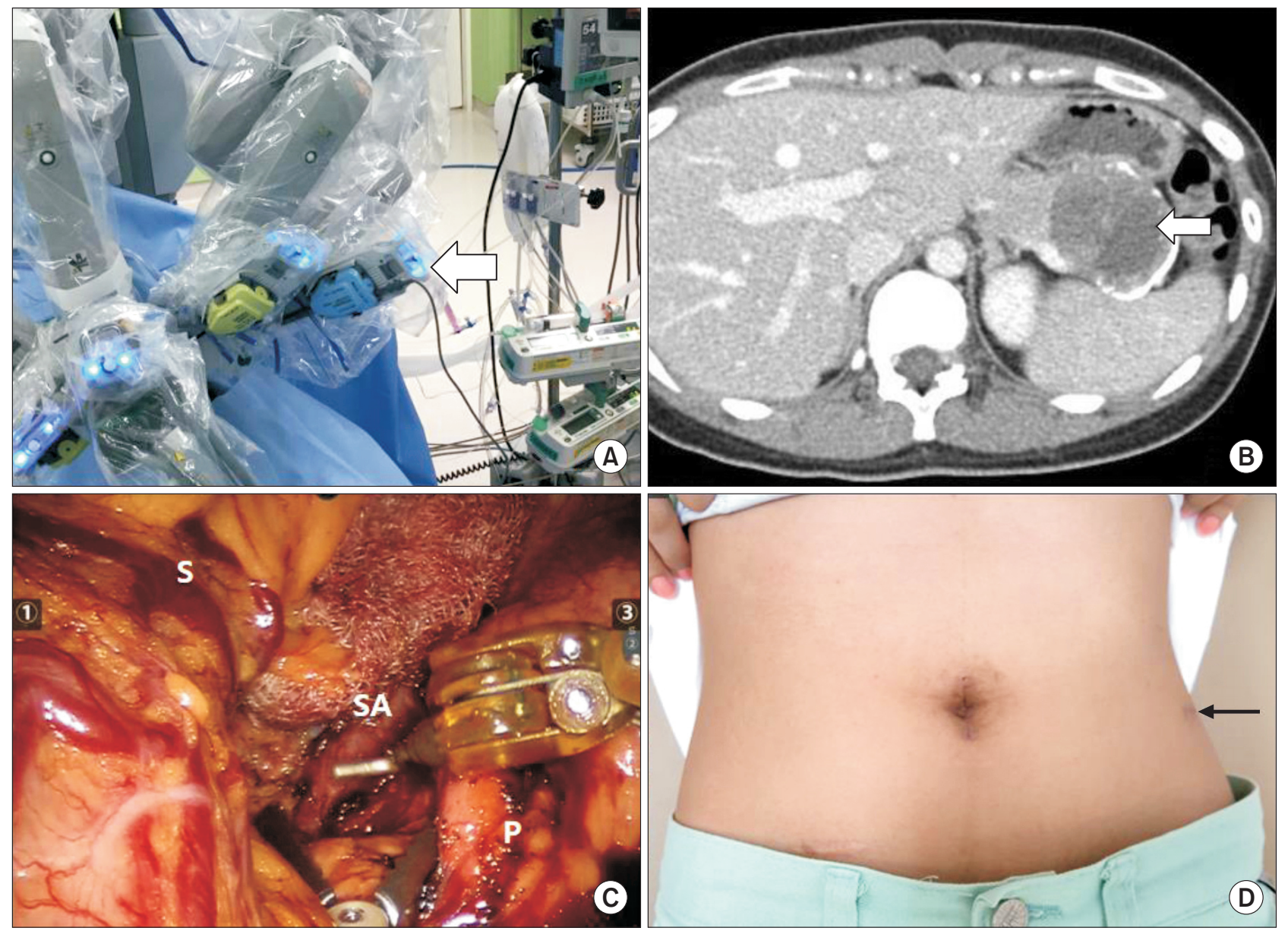

Fig. 2. Technical innovation of the robotic surgical system for LSP/RP DP. Robot setting for robotic single-site plus ONE port DP. Note a third robotic arm (white thick arrow) in the left lateral flank of the patient (three left-sided robotic arms) (A). Large pancreatic tumor with marginal calcification (white thin arrow) (B). The stomach was retracted with a single site robotic arm, and the splenic artery was effectively dissected using another robotic arm from the single-site robotic surgical system. A third robotic arm allowed for angulating wrist motion (C). Postoperative wound. Left lateral flank wound from the third robotic arm is away from the midline. The operative wound is hardly visible (black arrow) (D). $S=$ stomach; $S A=$ splenic artery; $P=$ pancreas. 
effective reduced-port surgery (Fig. 2A). Considering there is no wrist like-motion in pure robotic single site robotic surgical system, this technical advantages from additional port will be great helpful. In addition, preoperative surgical rehearsal is another advantage of robotic surgery. Surgical procedures can be simulated and techniques modified before applying them to patients, which allows for improved surgical quality and safety. Beginning in October 2015, we have been applying our robotic single-site plus ONE port DP technique in selected cases. A total of six cases, including a recent case of pancreatic enucleation, have already been performed safely using this new technique (unpublished).

A case of robotic single-site plus ONE port DP case is briefly introduced in this review. A 24-year-old female patient was admitted to the hospital due to the incidental finding of a mass in the pancreatic tail (Fig. 2B). Based on the presumed diagnosis of a solid pseudopapillary pancreatic neoplasm, she underwent robotic single-site plus ONE port DP. Total operation time was 160 minutes, and the estimated intraoperative blood loss was less than $50 \mathrm{ml}$. When dissecting splenic vessels, angulating motion of surgical instrument through additional port made surgical procedure effective and easy (Fig. 2C). No POPF was noted. She was discharged on the seventh postoperative day. Postoperatively, the wound appeared to be healing well (Fig. 2D). This case suggests that the main obstacles of the LSP/LRP system, which include surgical stress and ineffective instrument manipulation, can be resolved by using a robotic surgical system. More experience is required to determine the exact role of the robotic single-site surgical system for performing LSP/LRP-DP.

\section{CONCLUSION AND FUTURE PERSPECTIVES}

Despite the lack of randomized controlled studies, the accumulating number of LDP cases strongly suggests that LDP is a safe and effective surgical option for treating benign and borderline malignant tumors of the left pancreas. Currently, some efforts are being made to reduce the number of external wounds resulting from LSP/LRP-DP. LSP/LRP-DP is an emerging technique, and only a limited number of cases have been performed, however, the currently available published data show that LSP/LRP-DP is feasible, safe, and even comparable to conventional LDP. According to the literatures, a spleen-preserving procedure can be performed without increasing perioperative risk by this approach. It is difficult to estimate the limitations of instrumental movement and the surgeon's intraoperative stress and fatigue during LSP/LRPDP. However, these technical limitations may be obstacles to the widespread use of LSP/LRP-DP. Further technical innovation and advances are required for reliable minimally inva- sive LDP. It is expected that more reliable clinical data based on a larger number of patients will be published from expert laparoscopic surgeons in the near future. Minimally invasive surgeons will continue to work to reduce postoperative pain and number of external wound, increasing the quality of life associated with laparoscopic procedures.

\section{REFERENCES}

1) Soper NJ, Brunt LM, Dunnegan DL, Meininger TA. Laparoscopic distal pancreatectomy in the porcine model. Surg Endosc 1994;8:57-60; discussion 60-51.

2) Cuschieri A, Jakimowicz JJ, van Spreeuwel J. Laparoscopic distal $70 \%$ pancreatectomy and splenectomy for chronic pancreatitis. Ann Surg 1996;223:280-285.

3) Kang CM. Should we randomize our patients in the name of the "scientific evidence"? Surgery 2015;158:1742-1743.

4) Mehrabi A, Hafezi M, Arvin J, et al. A systematic review and meta-analysis of laparoscopic versus open distal pancreatectomy for benign and malignant lesions of the pancreas: it's time to randomize. Surgery 2015;157:45-55.

5) Xu AM, Huang L, Li TJ. Single-incision versus three-port laparoscopic appendectomy for acute appendicitis: systematic review and meta-analysis of randomized controlled trials. Surg Endosc 2015;29:822-843.

6) Yamazaki M, Yasuda H, Koda K. Single-incision laparoscopic cholecystectomy: a systematic review of methodology and outcomes. Surg Today 2015;45:537-548.

7) Carus T. Current advances in single-port laparoscopic surgery. Langenbecks Arch Surg 2013;398:925-929.

8) Barbaros U, Sumer A, Demirel T, et al. Single incision laparoscopic pancreas resection for pancreatic metastasis of renal cell carcinoma. JSLS 2010;14:566-570.

9) Haugvik SP, Rosok BI, Waage A, Mathisen O, Edwin B. Singleincision versus conventional laparoscopic distal pancreatectomy: a single-institution case-control study. Langenbecks Arch Surg 2013;398:1091-1096.

10) Han HJ, Yoon SY, Song TJ, et al. Single-port laparoscopic distal pancreatectomy: initial experience. J Laparoendosc Adv Surg Tech A 2014;24:858-863.

11) Lee H, Heo JS, Choi SH, Choi DW. Safety and Feasibility of Single Incision Laparoscopic Spleen Preserving Distal Pancreatectomy. J Minim Invasive Surg 2016;19:89-96.

12) Yao D, Wu S, Li Y, Chen Y, Yu X, Han J. Transumbilical singleincision laparoscopic distal pancreatectomy: preliminary experience and comparison to conventional multi-port laparoscopic surgery. BMC Surg 2014;14:105.

13) Machado MA, Surjan RC, Makdissi FF. First single-port laparoscopic pancreatectomy in Brazil. Arq Gastroenterol 2013;50:310312. 
14) The Korean Society of Endoscopic \& Laparoscopic Surgeons. The Korean Society of Endoscopic \& Laparoscopic Surgeons [Internet]. Bundang: The Korean Society of Endoscopic \& Laparoscopic Surgeons; c2008 [cited on Sep 20, 2016]. Available from: http:// www.ksels.or.kr/.

15) Ballantyne GH. Robotic surgery, telerobotic surgery, telepresence, and telementoring. Review of early clinical results. Surg Endosc 2002;16:1389-1402.

16) Hashizume M, Konishi K, Tsutsumi N, Yamaguchi S, Shimabukuro R. A new era of robotic surgery assisted by a computerenhanced surgical system. Surgery 2002;131:S330-333.

17) Qadan M, Curet MJ, Wren SM. The evolving application of singleport robotic surgery in general surgery. J Hepatobiliary Pancreat Sci 2014;21:26-33.

18) Lee SH, Jung MJ, Hwang HK, Kang CM, Lee WJ. The first experiences of robotic single-site cholecystectomy in Asia: a potential way to expand minimally-invasive single-site surgery? Yonsei Med J 2015;56:189-195.

19) Konstantinidis KM, Hirides $P$, Hirides $S$, Chrysocheris P, Georgiou M. Cholecystectomy using a novel Single-Site((R)) robotic platform: early experience from 45 consecutive cases. Surg Endosc 2012;26:2687-2694.

20) Morelli L, Guadagni S, Di Franco G, Palmeri M, Di Candio G, Mosca F. Da Vinci single site(c) surgical platform in clinical practice: a systematic review. Int J Med Robot 2016;12:724-734.

21) Nakamura M, Nakashima H. Laparoscopic distal pancreatectomy and pancreatoduodenectomy: is it worthwhile? A meta-analysis of laparoscopic pancreatectomy. J Hepatobiliary Pancreat Sci 2013;20:421-428.

22) Jin $\mathrm{T}$, Altaf K, Xiong JJ, et al. A systematic review and metaanalysis of studies comparing laparoscopic and open distal pancreatectomy. HPB (Oxford) 2012;14:711-724.

23) Sui CJ, Li B, Yang JM, Wang SJ, Zhou YM. Laparoscopic versus open distal pancreatectomy: a meta-analysis. Asian J Surg 2012;35:1-8.

24) Xie K, Zhu YP, Xu XW, Chen K, Yan JF, Mou YP. Laparoscopic distal pancreatectomy is as safe and feasible as open procedure: a meta-analysis. World J Gastroenterol 2012;18:1959-1967.

25) Venkat R, Edil BH, Schulick RD, Lidor AO, Makary MA, Wolfgang CL. Laparoscopic distal pancreatectomy is associated with significantly less overall morbidity compared to the open technique: a systematic review and meta-analysis. Ann Surg 2012;255:1048-1059.

26) Jusoh AC, Ammori BJ. Laparoscopic versus open distal pancreatectomy: a systematic review of comparative studies. Surg Endosc 2012;26:904-913.

27) Nigri GR, Rosman AS, Petrucciani N, et al. Metaanalysis of trials comparing minimally invasive and open distal pancreatectomies. Surg Endosc 2011;25:1642-1651.

28) Chang SK, Lomanto D, Mayasari M. Single-port laparoscopic spleen preserving distal pancreatectomy. Minim Invasive Surg 2012;2012:197429.

29) Morales-Conde S, Rubio-Manzanares M, Alarcon I, Barranco A, Socas M. [Single port distal pancreatectomy without spleen preserving]. Cir Esp 2013;91:541-543.

30) Kim EY, You YK, Kim DG, et al. Dual-incision laparoscopic spleen-preserving distal pancreatectomy. Ann Surg Treat Res 2015;88:174-177.

31) Misawa $T$, Ito R, Futagawa $Y$, et al. Single-incision laparoscopic distal pancreatectomy with or without splenic preservation: how we do it. Asian J Endosc Surg 2012;5:195-199.

32) Srikanth G, Shetty N, Dubey D. Single incision laparoscopic distal pancreatectomy with splenectomy for neuroendocrine tumor of the tail of pancreas. J Minim Access Surg 2013;9:132-135.

33) Machado MA, Surjan RC, Makdissi FF. Laparoscopic Distal Pancreatectomy Using Single-Port Platform: Technique, Safety, and Feasibility in a Clinical Case Series. J Laparoendosc Adv Surg Tech A 2015;25:581-585.

34) Zhao G, Hu M, Liu R, et al. Single-port retroperitoneoscopic pancreatectomy: preliminary results from the first 3 patients. J Clin Gastroenterol 2014;48:559-562.

35) Kuroki T, Adachi T, Okamoto T, Kanematsu T. Single-incision laparoscopic distal pancreatectomy. Hepatogastroenterology 2011;58:1022-1024. 